\title{
The high speed water tunnel facility at the Indian Institute of Science
}

\author{
V H ARAKERI, S D SHARMA ${ }^{1 *}, \mathrm{~K} \mathrm{MANI}^{1}$ and $\mathrm{H}$ S GOVINDA \\ RAM $^{2}$
}

Departments of ${ }^{1}$ Mechanical and ${ }^{2}$ Civil Engineering, Indian Institute of Science, Bangalore 560 012, India

* Present address: Department of Aeronautics, Indian Institute of Technology, Powai, Bombay 400 076, India

MS received 7 July 1988; revised 10 November 1988

\begin{abstract}
The present article about the high speed water tunnel facility at the Indian Institute of Science, Bangalore, provides a general description of the tunnel circuit, and brief reports on the performance of the facility and some typical results from investigations carried out in it. A unique aspect of the facility is that it has a horizontal resorber in the form of a large cylindrical tank located in the lower leg of the circuit. The facility has been used, among other things, for flow visualization studies, and investigations on marine propeller hydrodynamics and "synthetic cavitation". The last topic has been primarily developed at the Indian Institute of Science and shows considerable promise for basic work in cavitation inception and noise.
\end{abstract}

Keywords. Water tunnel; hydrodynamics; cavitation; flow visualization; marine propellers.

\section{Introduction}

The high speed water tunnel has become an indispensable tool in the study of cavitation which is a common occurrence in devices which handle high speed liquid flows. Water tunnels have been used not only to conduct model studies of prototype situations but also to generate the necessary scaling laws to extrapolate model test results to prototype conditions. In addition, water tunnels have also been used to conduct basic studies in incipient and developed cavitation. In the future, these studies will probably play an increasingly important role in evolving accurate designs of components which may be less prone to cavitation under otherwise identical operating conditions. However, it would be a very limited point of view to imagine that water tunnels can or should be used exclusively for cavitation studies since they have been useful in studying other hydrodynamic aspects of the flow around solid bodies as well. Some of the physical properties of water which differ from those of air can be exploited. For example, for a given size and test section velocity, the Reynolds number in water flow will be about fifteen times the corresponding Reynolds number in air flow. In addition, for a given

A list of symbols is given at the end of the paper. 
velocity the magnitude of the dynamic head $H_{d}$ in water flow is about 800 times the dynamic head in the corresponding air flow. Thus, measurement of turbulent pressure fluctuations, which are generally proportional to the dynamic head, can be a much simpler task in the water medium than in air. Besides the above two advantages, the fact that the index of refraction of water is a very sensitive function of temperature as compared to that in air can also be usefully exploited for optical flow visualization by shadowgraph, schlieren and interferometric techniques. Slight heating is sufficient to crcate density gradients which become clearly visible. In addition, water is an excellent medium for conducting flow visualization studies using nonoptical techniques like hydrogen bubble, dye injection and oil film methods.

Thus, a water tunnel can be a very useful facility to study many aspects of fluid flow problems. With this in mind, a high speed water tunnel (HSWT) facility has been established at the Indian Institute of Science (IISc). In the present article, a general description of the facility is first provided. This is iollowed by a description of the performance aspect of the facility, and finally, some of the studies that have been carried out using the facility are discussed.

\section{General description of the water tunnel}

The IISC-HSWT facility is a closed loop circuit with interchangeable closed-jet and open-jet test sections and is equipped with a horizontal resorber. A schematic sketch of the water tunnel circuit with the closed-jet test section in place is shown in figure 1. The pertinent operating parameters of the tunnel are summarized in table 1 and these compare quite favourably with some of the large water tunnel facilities existing elsewhere (Holl \& Wood 1964). In the following, a brief description of the circuit is provided with an indication of the available instrumentation.

As indicated, the IISC-HSWT facility is equipped with two test sections; one, a closed-jet test section of $381 \mathrm{~mm}$ constant inner diameter having an overall length of $1520 \mathrm{~mm}$, and the second, an open-jet test section of $460 \mathrm{~mm}$ diameter having an overall length of $690 \mathrm{~mm}$. Both the test sections are provided with four plexiglass windows for photographic and observational purposes. The closed-jet test section has primarily been used for hydrodynamic studies on axisymmetric headforms, whereas the open-jet test section has been used for studies on marine propellers with diameters upto $250 \mathrm{~mm}$. The geometrical and constructional details of the two test sections are in Arakeri \& Govinda Ram (1978) and Mani (1984). The closed-jet test section is preceded by a contraction cone whose shape is based on a method described by Thwaites (1946). In the present facility, with the closed-jet test section in place, a contraction ratio of 16 is provided and it is relatively high compared to many other water tunnel facilities of similar size. The high contraction ratio definitely has a favourable influence on the flow quality in the test section. In addition to the high contraction ratio, further flow corrective devices have been incorporated in the present facility. These consist of guide vanes (typically thirty) at all the $90^{\circ}$ bends and a honey comb in the settling chamber having square cells measuring $25.4 \mathrm{~mm} \times 25.4 \mathrm{~mm}$ and with a length of $127 \mathrm{~mm}$ giving an aspect ratio of five. The closed-jet test section is followed by a transition section of parabolic inner shape and it smoothly joins the corresponding slopes at the end of the test section and the beginning of the diffuser. For the open-jet test section, the transition has been included as part of the test section itself. The two test sections, the 
Water tunnel facility at IISc
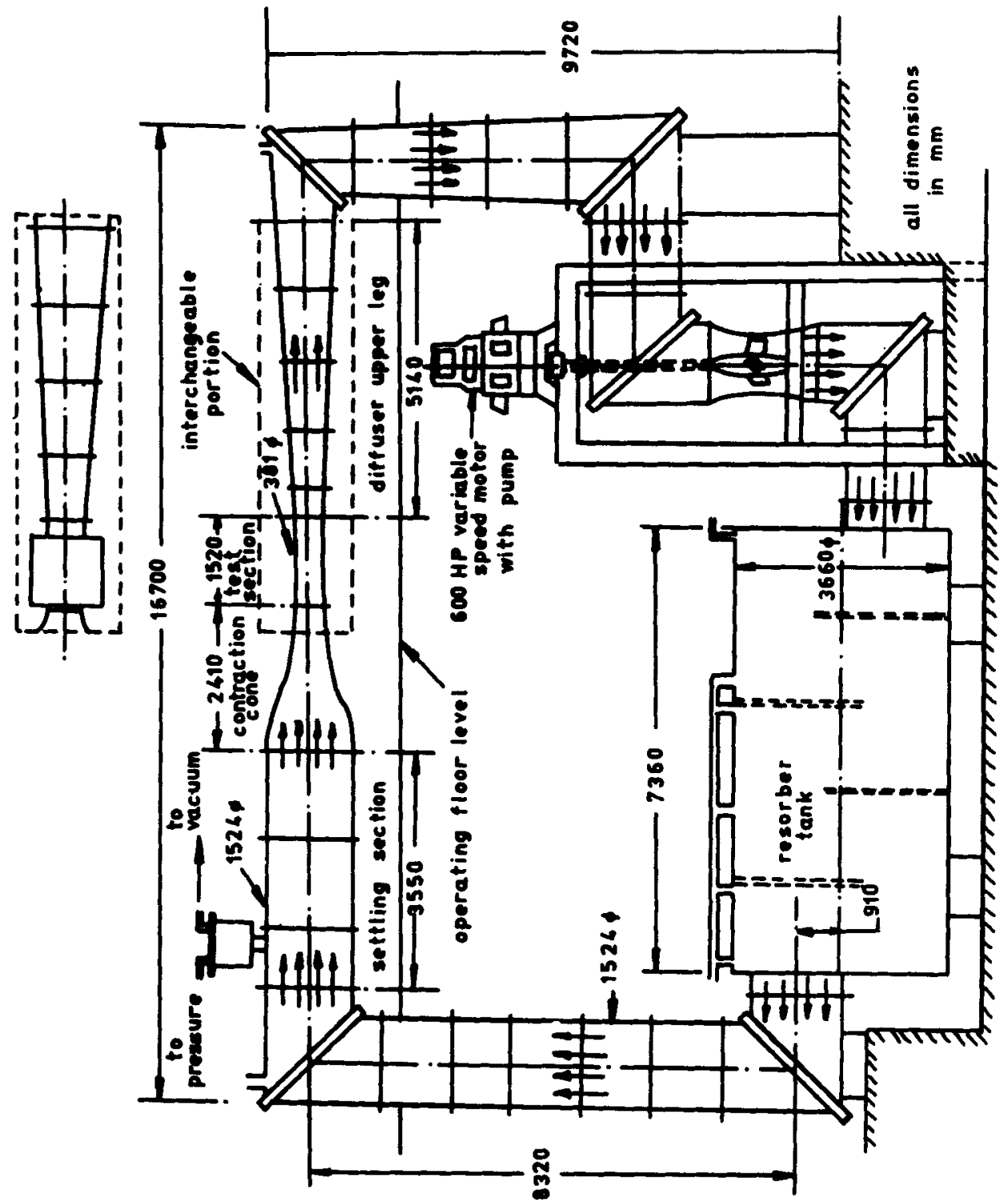
Table 1. Pertinent operating parameters of IISc-HSWT.

\begin{tabular}{lcc}
\hline Parameter & Closed-jet & Open-jet \\
\hline Test-section size (diameter) & $381 \mathrm{~mm}$ & $460 \mathrm{~mm}$ \\
Contraction ratio & $16: 1$ & $11: 1$ \\
Maximum velocity & $30.3 \mathrm{~m} / \mathrm{s}$ & $20.8 \mathrm{~m} / \mathrm{s}$ \\
Turbulence level & $0 \cdot 2-0.3 \%$ & Not measured \\
Maximum test-section pressure (absolute) & $2.5 \mathrm{bar}\left(2.5 \times 10^{5} \mathrm{~Pa}\right)$ \\
Minimum test-section pressure (absolute) & $0.33 \mathrm{bar}$ \\
Capacity of the drive motor & \multicolumn{2}{c}{$447.4 \mathrm{~kW}$} \\
\hline
\end{tabular}

contraction cone and the transition section, being critical components of the circuit, have been fabricated from gun metal. The remaining components of the circuit, including the diffuser which has an overall divergence angle of $6^{\circ}$ have been fabricated from mild steel plates.

During cavitation studies, the flowing liquid in a water tunnel is exposed to low pressures in the test section and this can result in dissolved air coming out of solution in the form of macroscopic free air bubbles. If these are not subjected to high pressures for sufficiently long periods of time, they may persist in the test section upstream of the test body. The presence of macroscopic air bubbles, in large numbers, could have undesirable effects in terms of obscuring the view of the test body, influencing the far field hydrodynamic or cavitation noise measurements and affecting the basic viscous flow past the test body. In some quarters, it is argued that the presence of these bubbles is a desirable feature in terms of providing nucleation sites for cavitation onset. Here, we will not debate on whether the presence of these bubbles is a desirable or an undesirable characteristic of a water tunnel. However, depending on the application, some control is perhaps desirable. This is achieved by incorporating an additional component in the tunnel circuit commonly termed as a "resorber". Several resorber designs are possible as indicated by Silverleaf (1958) and as a compromise between effectiveness and cost, a horizontall resorber has been incorporated in the present facility. The resorber is a $7.63 \mathrm{~m}$ long cylindrical tank, $3.66 \mathrm{~m}$ in diameter, and its bottommost point lies $9.1 \mathrm{~m}$ below the centre-line of the test section. To avoid dead water zones, four baffle plates of semi-circular shape are welded to form openings at the top and bottom, respectively, and these are shown by dotted lines in figure 1 .

The main circulating pump of the water tunnel is a four-bladed, fixed pitch, axial flow type of pump manufactured by Byron and Jackson Ltd., Los Angeles, USA. The pump is driven by a wound-rotor induction motor having a synchronous speed of $750 \mathrm{RPM}$ and a power rating of $447.4 \mathrm{~kW}(600 \mathrm{hp})$. Test-section speed variation is achieved by varying the rotor winding resistance through a liquid rheostat control. The disadvantage of this type of speed regulator is the limited range (normally 2:1) within which speed control is possible. However, a wound-rotor induction motor with a liquid rheostat control, was at the time of design a low cost solution to the requirements of the water tunnel. To conduct cavitation studies, it is also necessary to control the test-section static pressure independent of the velocity. In the present facility, this is achieved by the pressure control in an airchamber located above the settling-chamber upstream of the contraction cone.

The major instruments available with the water tunnel facility are: Brüel \& Kjaer range of noise measuring equipment, seven-channel instrumentation tape recorder, 
DISA-laser doppler velocitimeter (LDV), EG and G high-speed stroboscope, Fastax WF-2 high speed motion picture camera, six-component strain-gauge balance, propeller dynamometer and Kempf and Remmers model D-25 machine for fabrication of model marine propellers.

\section{Performance studies of the water tunnel}

Even though the facility was erected during the period 1964-1968, its actual active use has been only since 1978. Subsequent to its initial erection, the major improvement/additions have been the internal sand-blasting of the entire facility and application of two coats of zinc-rich primer of about $25 \mu \mathrm{m}$ thickness each and three coats of coal-tar epoxy paint of approximately $80 \mu \mathrm{m}$ each. This was performed in 1981 and so far there are no signs of major rust problems. In 1983, the interchangeable open-jet test section was added.

The first set of cavitation studies carried out using the facility are reported in Arakeri \& Govinda Ram (1981). Prior to this, numerous facility performance observational studies were carried out. These clearly brought out certain limitations in the design of the facility. A major drawback is the use of flat end plates in the resorber section. These deflect substantially under pressurization such that the movements alter the small clearances existing at the impeller resulting in rubbing of blades with the casing. Another drawback, though relatively minor, is the dependence on rubber gaskets between flange joints for prevention of leakage. Overall, the facility was found to operate quite satisfactorily up to a maximum test-section velocity of about $22 \mathrm{~m} / \mathrm{s}$. Qualitative observations were also carried out on the performance of the resorber. It was found that very few or no macroscopic free-stream air bubbles are seen with the test-section cavitation number, $\sigma$, values greater than 0.4 at a testsection velocity of $10 \mathrm{~m} / \mathrm{s}$. The presence of a resorber in a tunnel circuit has certain other implications on the performance of the facility. First of all, due to the large volume of water involved, the temperature rise due to continuous operation is not sufficient to warrant external cooling devices. In the present facility, the resorber accounts for about two-thirds of the total volume of $135 \mathrm{~m}^{3}$ and the temperature rise has been found to be only of the order of $1^{\circ} \mathrm{C}$ over a continuous operating period of $6 \mathrm{~h}$ at a test-section velocity of $15 \mathrm{~m} / \mathrm{s}$.

The disadvantage of having a large volume of water is that it is difficult to control the dissolved air content value without having as a bypass, an external deaerater system. In the present facility, a limited reduction in the dissolved air content value is achieved by the following procedure. A body (typically disk) is made to cavitate heavily in the test section and the free air released during this process, collects at the top of the resorber tank and this is bled off periodically.

More recently, quantitative performance studies on certain critical components of the circuit have been carried out and these will be indicated next. The measured pressure drop along the contraction cone is shown in figure 2. It is clear that the pressure reduces quite smoothly and monotonically as expected from design considerations. The solid line in figure 2 is the computed pressure drop based on simple area considerations. The measured pressure drop along the closed-jet test section is shown in figure 3 and the magnitudes appear to be typical of some other facilities (Lehman 1959; Ward 1977). The measured axial velocity distribution across the closed-jet test section in a horizontal plane perpendicular to the flow direction and 


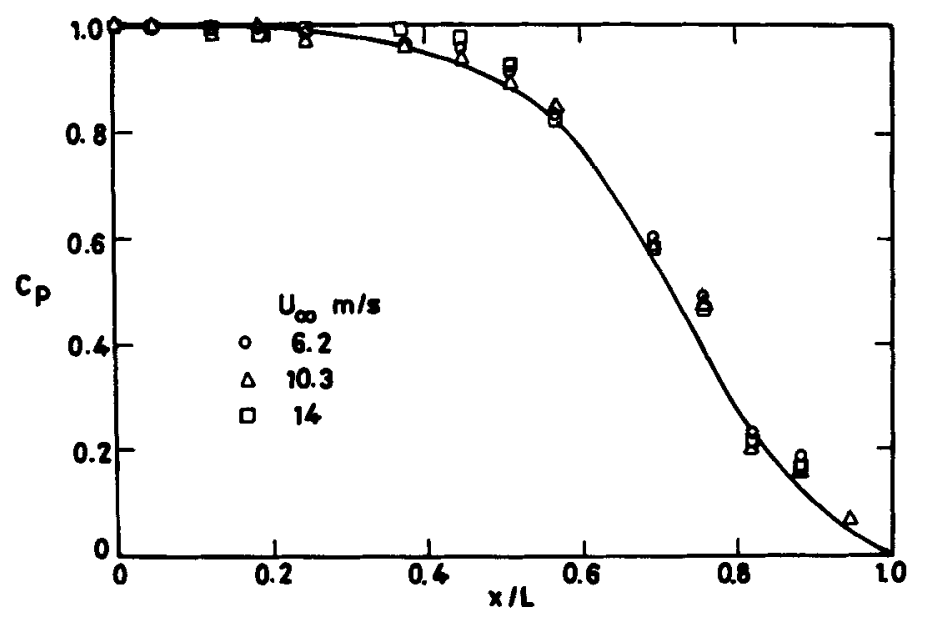

Figure 2. Measured pressure drop in contraction. Solid line is predicted pressure drop based on area consideration.

at an axial location of $545 \mathrm{~mm}$ from the inlet is shown in figure 4. The DISA-LDV in the forward scatter mode was used for these measurements, and in view of this, on the far side it was difficult to get reliable measurements near the wall. The axial turbulence level at the centre of the test section was also measured and had normalized values of $0.39 \%$ at $U_{\infty}=7 \mathrm{~m} / \mathrm{s}, 0.25 \%$ at $U_{\infty}=10 \mathrm{~m} / \mathrm{s}$ and $0.19 \%$ at $U_{\infty}=12 \mathrm{~m} / \mathrm{s}$. The measured values compare very favourably with the turbulence levels quoted for the California Institute of Technology (CIT) high speed water tunnel facility by Ward (1977). It is pertinent to point out that the present facility and the CIT facility are of similar sizes and both have a contraction ratio of 16 . The measurements reported above clearly show that the quality of test-section flow is good enough to carry out even fundamental hydrodynamic studies.

Water tunnel facilities are increasingly being used for hydroacoustics studies including cavitation noise measurements. In view of this, knowledge of the background noise levels in a facility is useful. Figure 5 shows two sets of background noise level measurements in the present facility. One set corresponds to levels measured with the help of a flush-mounted pressure transducer $(6.4 \mathrm{~mm}$ diameter) on the tunnel wall. The second set of measurements were made with a hydrophone placed inside a flooded cavity which was surrounded with a streamlined plexiglass nose. The details of these measurements are given in Sharma \& Arakeri (1985); however, it may be noted that they represent "ambient" noise levels at the centre of the test section. A peak at frequency of about $1 \mathrm{kHz}$ observed with these measurements is associated with the vibration of the hydrophone. The

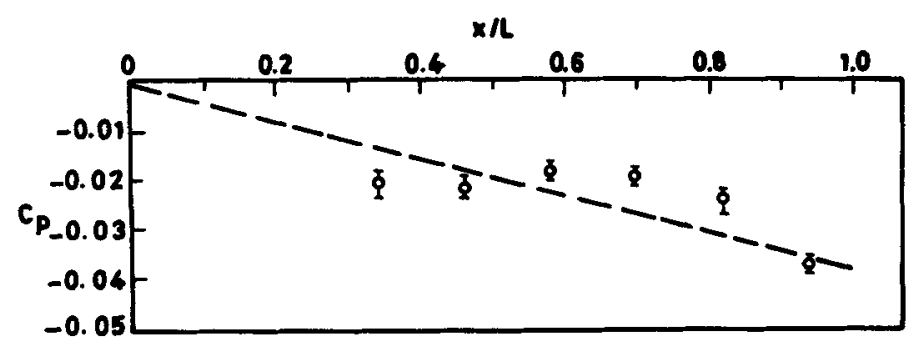

Figure 3. Measured pressure drop in closed-jet test section $\left(U_{\infty}=10 \mathrm{~m} / \mathrm{s}\right)$. 


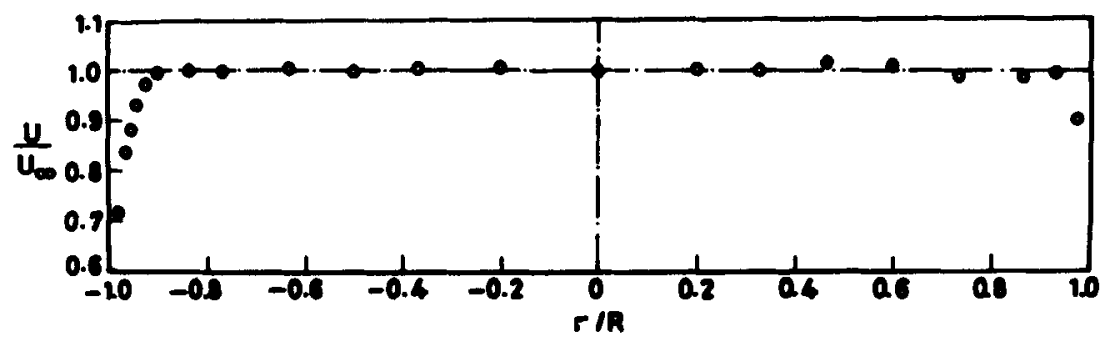

Figure 4. Velocity distribution in closed-jet test section. Looking in the direction of flow, negative values of $r / K$ correspond to the right side of the test-section $\left(U_{\infty}=10 \mathrm{~m} / \mathrm{s}\right)$.

difference in the levels measured by the two techniques is due to the fact that in one case the sensitive part of the transducer is exposed directly to the turbulent flow; whereas in the other case it is shielded from it. Therefore, noticeable differences are observed at lower frequencies. The noise levels measured in the present facility are comparable to those measured in a few other water tunnel facilities.

\section{Typical studies using the facility}

Over the last decade, the facility has been used for several investigations which can be classified as basic and applied. So far very little development work has been undertaken. As representative typical investigations, three studies will be highlighted and these are; (a) flow visualization studies on a sphere, (b) marine propeller hydrodynamic studies, and (c) studies with "synthetic cavitation".

\subsection{Flow visualization on a sphere}

A schlieren flow visualization set-up very similar to the one described in Arakeri \& Acosta (1973) was developed here (Arakeri \& Govinda Ram 1981). For this, a high

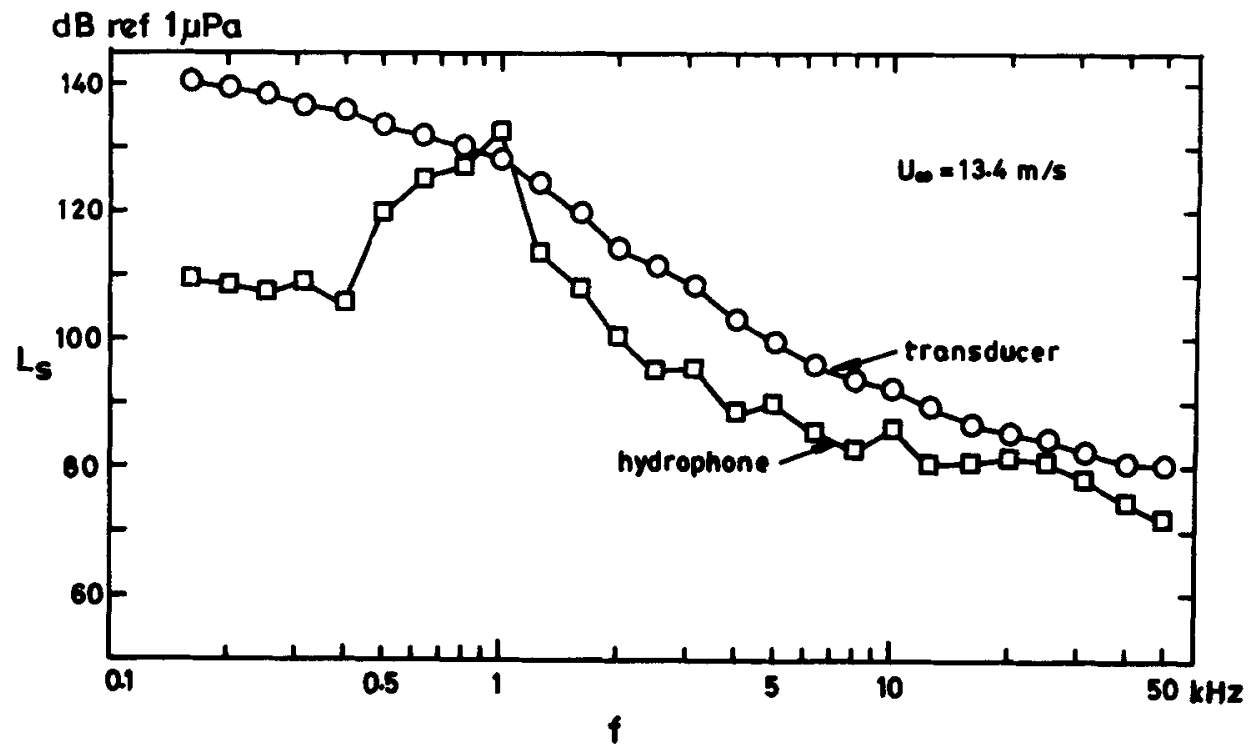

Figure 5. Measured tunnel background noise levels. 
intensity and short duration spark source was fabricated, and correction lenses were designed to overcome the difficulties associated with the curved test-section windows. In addition, a feature which enables considerable improvement in the quality of schlieren photographs is the filling up of the gap between the correction lens and the window with glycerine, a refractive index matching fluid. The main aim of the study was to observe the viscous flow past a sphere near its critical Reynolds number. The observations, as reported in Arakeri \& Govinda Ram (1984), clearly showed that below the critical Reynolds number, only laminar separation prevails with the separation point being near $80^{\circ}$ from the stagnation point, and just above the critical Reynolds number, laminar separation near $101^{\circ}$ is followed by turbulent reattachment and subsequent turbulent separation at about $135^{\circ}$. Going through the critical Reynolds number, the laminar separation point was observed to gradually shift downstream from 80 to $101^{\circ}$. The set of photographs in figure 6 clearly shows this phenomenon. In addition, it is observed that the separating streamline, in each case, leaves almost tangentially to the solid surface.

\subsection{Marine propeller hydrodynamic studies}

Considerable impetus to cavitation research has been associated with prototype cavitation problems on marine propellers, whether be it for civilian or defence applications. The complete infrastructure has been developed at the IISc-HSWT facility for marine propeller testing work as described in Arakeri et al (1984). This includes addition of the new open-jet test section, facility for model marine propeller fabrication, techniques and instrumentation for force measurements, cavitation noise measurements and wake simulation. Even though model marine propellers are driven with a relatively long shaft system $(7.5 \mathrm{~m})$, with careful alignment of the support system with a laser and the use of teflon as bearing material, very low background noise levels have been achieved. The reduction in noise levels with these improvements are shown in figure 7. Also shown are noise levels from a three-bladed $250 \mathrm{~mm}$ model marine propeller with tip-vortex cavitation; these levels are significantly above the background noise levels over most of the frequency range.

Extensive sturdies have been carried out to determine the cavitation inception and noise characteristics of different design marine propellers. In addition, attempts are being made to devise techniques for cavitation inception delay and cavitation noise reduction. One method which seems to show some promise is the drilling of very small holes $(0.3 \mathrm{~mm})$ in the leading edge area of the propeller blades. Figure 8 , taken from Arakeri et al (1985, pp. 29-30), shows that the inception number for tip-vortex type of cavitation is delayed by the use of this technique. Further studies are underway to determine its influence on cavitation noise levels. Preliminary findings show that there are significant effects in the low frequency part of the spectrum, in particular at low advance coefficients.

\subsection{Studies with synthetic cavitation}

The term "synthetic cavitation" has been used by Arakeri (1986, pp. 77-86) to describe cavitation which has been generated by seeding the flow with artificial nuclei. The technique, which has been primarily developed at the Indian Institute of Science, consists of implanting electrodes in the stagnation region of axisymmetric bodies made of a non-conducting material like perspex. A d.c. voltage applied 

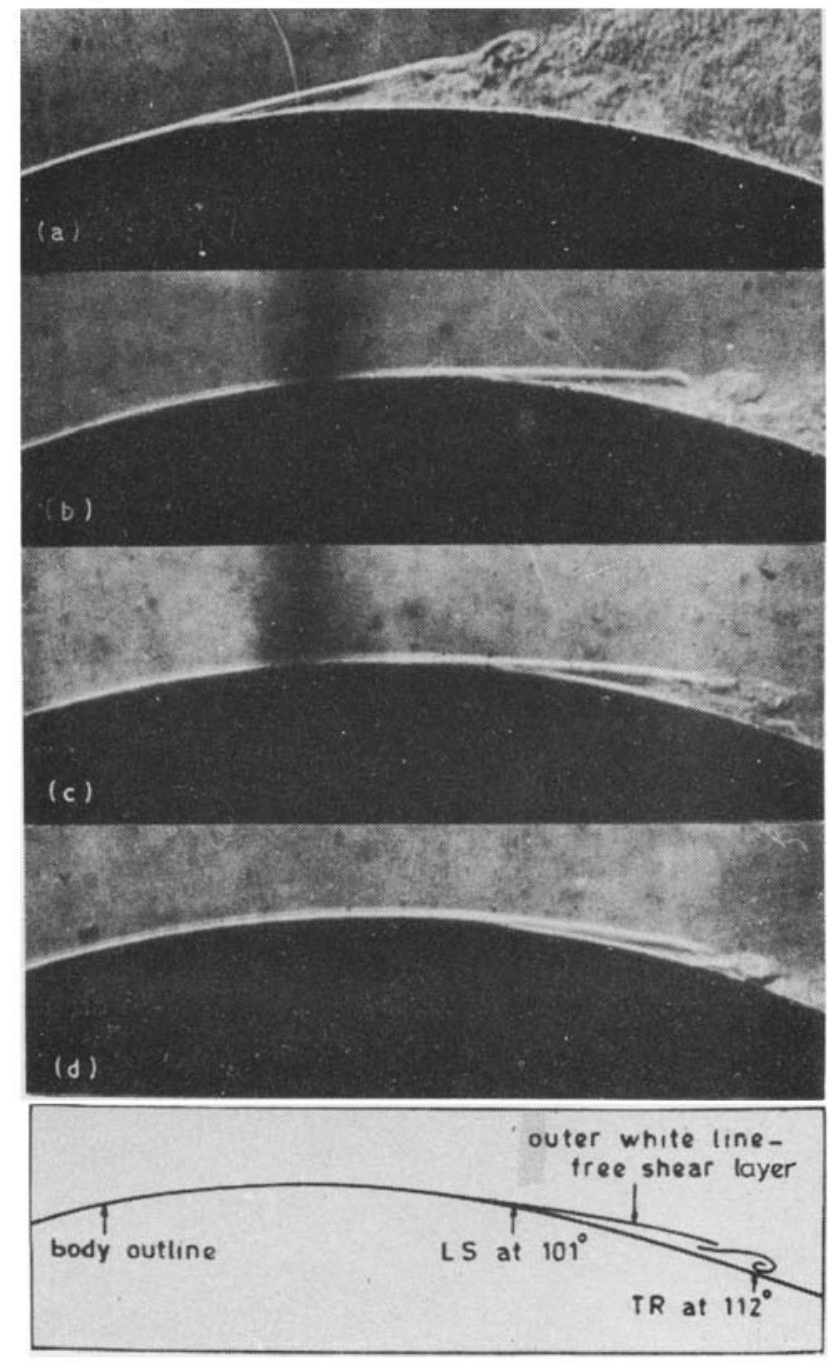

Figure 6. Shift of laminar separation $\left(L_{s}\right)$ on a sphere. (a) $\operatorname{Re}=1.7 \times 10^{5}, L_{s}$ at $80^{\circ}$; (b) $\operatorname{Re}=2.5 \times 10^{5}, L_{s}$ at $93 \%$ (c) $\operatorname{Re}=2.8 \times 10^{5}, L_{\mathrm{s}}$ at $95^{\prime}$; (d) $\operatorname{Re}=3.5 \times 10^{5}, L_{\mathrm{s}}$ at $101^{\prime}$. Flow is from left to right (from Arakeri \& Govinda Ram 1981).

across this electrode and the tunnel wall results in the generation of hydrogen or oxygen bubbles by electrolysis, and these serve as nuclei for cavitation. Typically, it is possible to seed 50-micron size bubbles. By altering the geometrical configuration of the electrodes, the magnitude of the d.c. voltage and the polarity of the electrodes, it is possible to generate "controlled" travelling bubble type of cavitation. The technique has been explored for several investigations which have been fully described in Shanmuganathan \& Arakeri (1981, pp. 131-164), Arakeri \& Shanmuganathan (1986) and Iyer (1985). Figure 9 taken from Iyer (1985) shows that the results of cavitation inception observations on four geometrically similar bodies of a particular shape (known as Schiebe body. Schiebe 1982), with and without seeding, by electrolysis. Under natural conditions, $\sigma_{i}$ values, irrespective of the body 


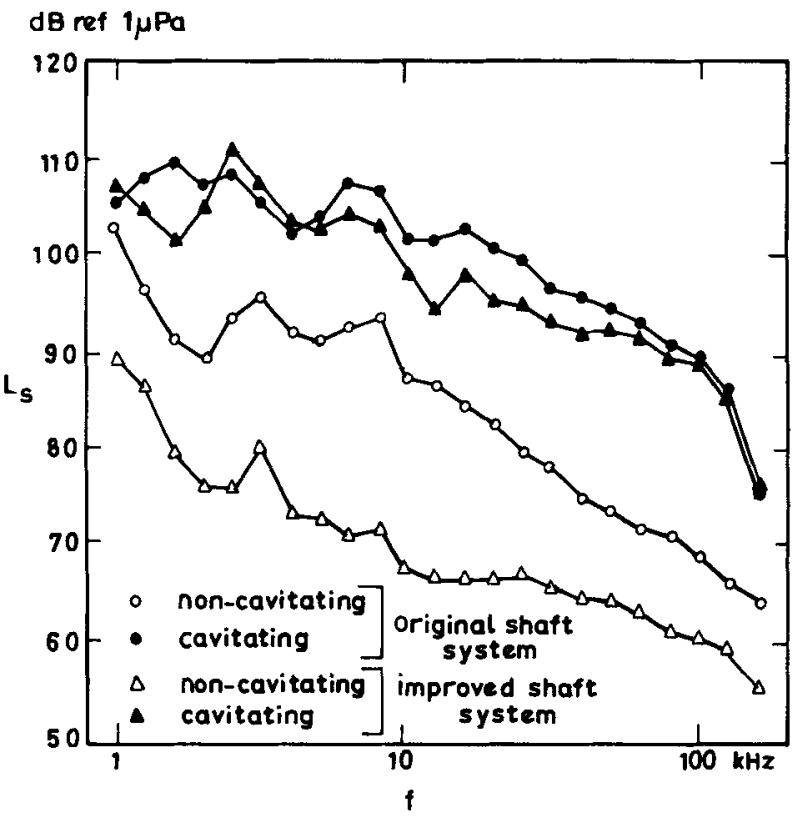

Figure 7. Measured noise levels from a marine propeller $(J=0.67$, $\sigma / \sigma_{i}=0 \cdot 74$ ) (from Mani 1987).

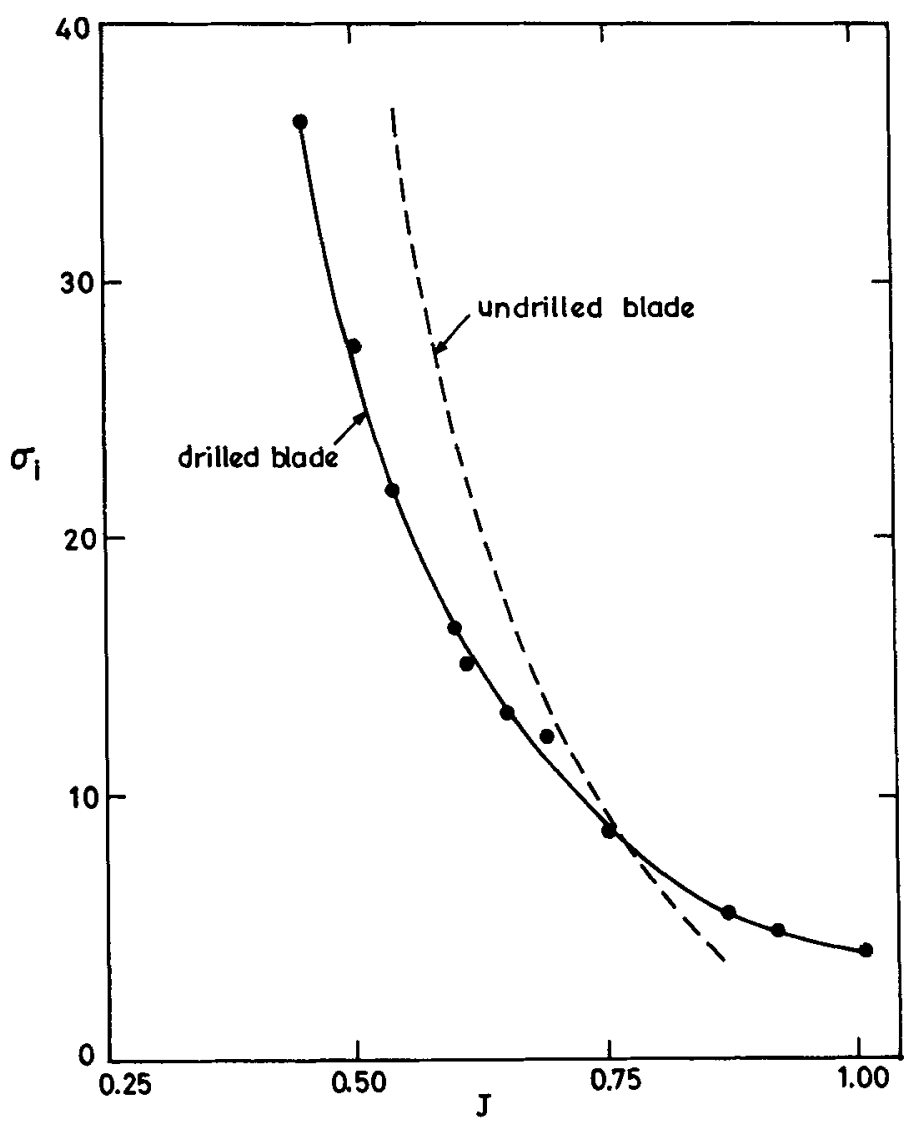

Figure 8. Influence of blade modification on inception of tip vortex cavitation from a marine propeller (from Arakeri et al 1985). 


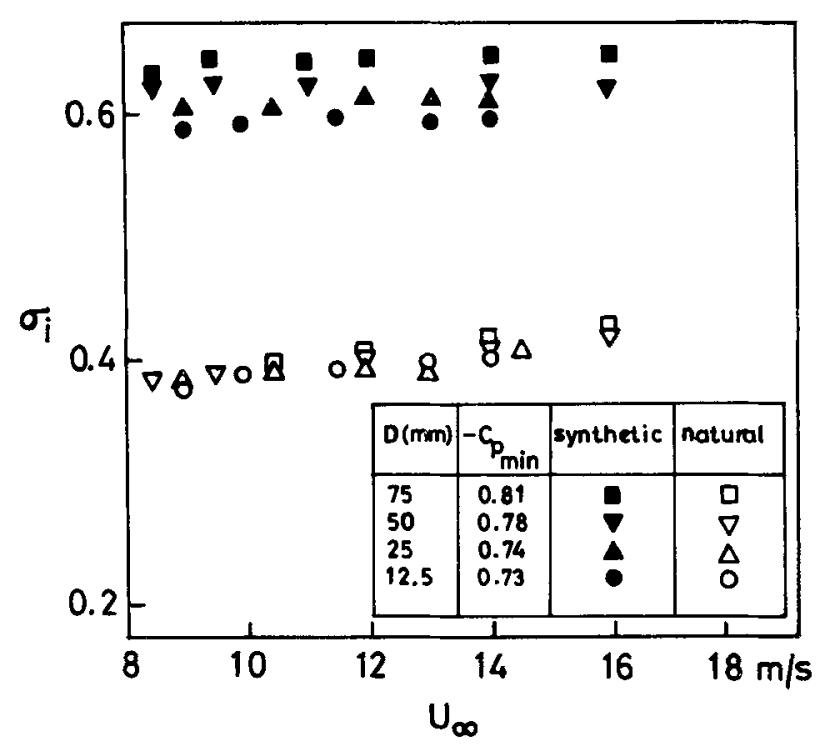

Figure 9. Cavitation inception index on four geometrically similar bodies with and without seeding (from Iyer 1985).

size are close to $0 \cdot 4$, being significantly lower than the unblocked $-C_{p_{\min }}$ value of $0 \cdot 75$. The reason for this is most likely associated with the fact that, in the present circuit, the resorber is found to be very effective up to a test-section $\sigma$ value of 0.4 . With seeding, $\sigma_{i}$ values are found to be much higher, being close to 0.6 and they show a dependence on body size which is proportional to the change in the $-C_{p_{\min }}$ value due to blockage effects. Figure 10 shows the synthetic cavitation noise levels from a $50 \mathrm{~mm}$ Shiebe body. The insert in the figure shows a photograph of the synthetic cavitation.

It is very clear that strong scale effects on cavitation noise are possible depending on the nuclei content of the liquid. That is, at the same $\sigma$ value, substantial differences in noise levels are observed with and without electrolysis.

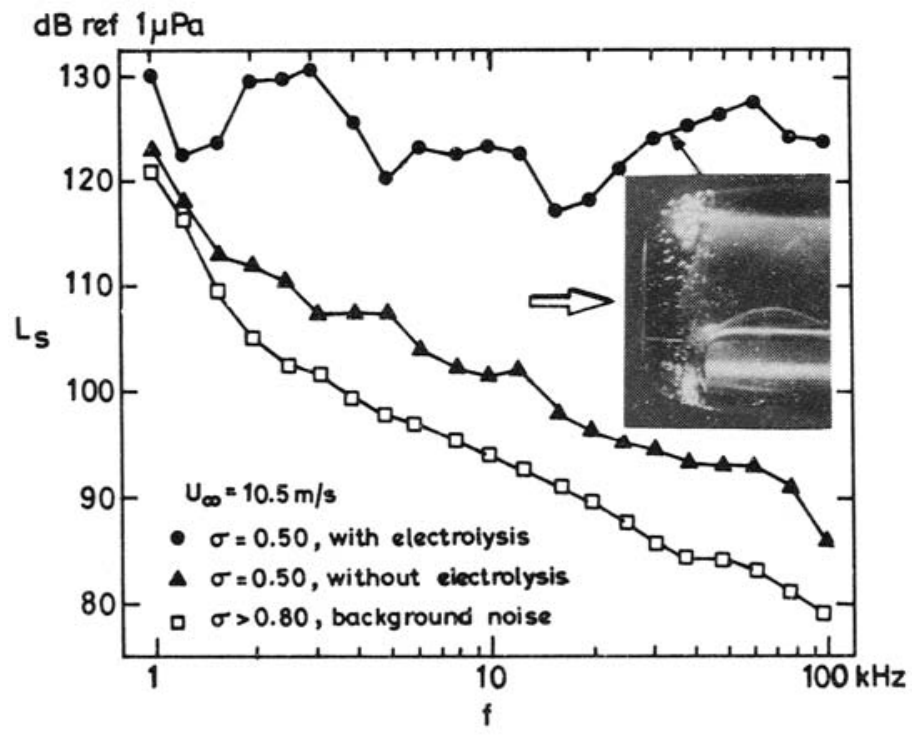

Figure 10. Synthetic cavitation noise from a "Schiebe" body. Increase in noise levels without electrolysis is due to support cavitation. 


\section{Concluding remarks}

The high speed water tunnel facility at the Indian Institute of Science has been found to be a very useful tool for cavitation and other hydrodynamic studies. Experience indicates that working with large water tunnel facilities is both a difficult and an expensive proposition. Therefore, facilities set-up at Educational Institutions should not cater to very high speed requirements and large test-section sizes. Instead, the facility should be made as versatile as possible, so that the multitude of various types of investigations like flow visualization studies, cavitation studies, high Reynolds number hydrodynamic studies and hydroacoustics studies are undertaken. Therefore, future facilities should incorporate certain novel features like good optical quality windows (or inserts), nuclei, turbulence and ambient noise management devices.

The Indian Institute of Science High Speed Water Tunnel owes its existence to the vision of Professor N S Govinda Rao. The facility was designed by the late Mr Nanjundaswamy under the supervision of Professor K Seetharamaiah who was instrumental in its fabrication and installation. All the tunnel components except for the main motor and pump were fabricated by M/s Tungabhadra Steel Products Ltd., Hospet, Karnataka. The financial support for the design, fabrication and installation of the high speed water tunnel facility was given by the Central Board of Irrigation and Power, Government of India. The financial grant for the construction of the building to house the facility has been provided by the University Grants Commission, New Delhi. Financial support for the addition of the open-jet test section and procurement of all the instruments listed has been given by the Department of Electronics/Electronics Commission under its technology development projects.

\section{List of symbols}

$C_{p} \quad$ pressure coefficient, $\left(p-p_{\infty}\right) / H_{d} ;$

$C_{p_{\min }}$ minimum pressure coefficient;

$D$ reference diameter;

$f \quad$ frequency;

$H_{d}$ dynamic head, $\frac{1}{2} \rho U_{\infty}^{2}$;

$J$ advance coefficient, $U_{\infty} / n D$;

$L$ contraction cone or test section length;

$L_{s} \quad$ noise levels corrected to $1 \mathrm{~Hz}$ bandwidth;

$n$ rotational speed of propeller in rps;

$p \quad$ local static pressure;

$p_{v} \quad$ vapour pressure;

$p_{\infty} \quad$ free stream static pressure;

$r$ local radius;

$R$ tunnel wall radius;

Re Reynolds number, $U_{\infty} D / v$;

$U$ local velocity; 
$U_{\infty}$ free stream velocity;

$x \quad$ axial distance from beginning of contraction or test section;

$v \quad$ kinematic viscosity;

$\rho$ density;

$\sigma \quad$ cavitation number, $\left(p_{\infty}-p_{v}\right) / H_{d}$;

$\sigma_{i} \quad$ magnitude of $\sigma$ at inception.

\section{References}

Arakeri V H 1986 Proc. of the Speciality Conference on advancements in aerodynamics, fluid mechanics and hydraulics (New York: ASCE)

Arakeri V H, Acosta A J 1973 J. Fluid Eng. 95: 519-527

Arakeri V H, Govinda Ram H S 1978 Comparative cavitation inception studies on a hemispherically nosed body, WTL Report No. 78-1, Indian Institute of Science, Bangalore

Arakeri V H, Govinda Ram H S 1981 Flow visualization studies on a sphere near its critical Reynolds number, Report No. WTL-CSIR/TR. 81.1 Indian Institute of Science, Bangalore

Arakeri V H, Govinda Ram H S 1984 Curr. Sci. 53: 180-182

Arakeri V H, Munjal M L, Mani K, Richard K, Sharma S D 1984 Noise characteristics of marine propellers, Report No. DE-NRC/TDP-25/79-84, Indian Institute of Science, Bangalore

Arakeri V H, Shanmuganathan V 1986 J. Fluid Mech. 159: 131-150

Arakeri V H, Sharma S D, Mani K 1985 Cavitation and multiphase flow forum (New York: ASME)

Holl J W, Wood G M (eds) 1964 Cavitation research facilities and techniques (New York: ASME)

Iyer N 1985 An experimental study on scale effects on cavitation noise, Ph.D. thesis, Indian Institute of Science, Bangalore

Lehman A F 1959 The Garfield Thomas water tunnel, ORL Report No. 16597-56, State College, Penn. State University

Mani K 1984 Design of open jet test section for an existing high speed water tunnel facility, Report No. DE-NRC/TDP-25/TR-11, Indian Institute of Science, Bangalore

Mani K 1987 Cavitation inception and noise studies on marine propellers, Ph.D. thesis, Indian Institute of Science, Bangalore

Schiebe F R 1982 Measurements of cavitation susceptibility of water using standard bodies, Report No. SAFHL-1 18 University of Minneapolis, Minneapolis

Shanmuganathan V, Arakeri V H 1981 Fourteenth symp. on naval hydrodynamics (Washington, DC: National Academic Press)

Sharma S D, Arakeri V H 1985 An experimental study to assess the significance of flow transition on flow noise, Report No. DE-NRC/TDP-59/TR-3, Indian Institute of Science, Bangalore

Silverleaf A 1958 The design of a resorber for a water tunnel Ship, Div. Report No. 1, Natl. Phys. Lab., England

Thwaites B 1946 On the design of contractions for wind tunnels, ACR R and M No. 2278 (England)

Ward T M 1977 The hydrodynamics laboratory at the California Institute of Technology-1976, ASME Paper No. 77-FE-12, Joint Applied Mech., Fluids Eng. and Bio-Eng. Conf. New Haven 